\title{
LOS “PIONEROS” DEL MOVIMIENTO OBRERO RIOCUARTENSE Y LA HUELGA DEL AÑO 1936 COMO MANIFESTACIÓN DE CULTURA OBRERA EN EL INTERIOR ARGENTINO
}

\author{
THE "PIONEERS" OF THE LABOR MOVEMENT \\ RIOCUARTENSE AND THE STRIKE OF THE YEAR 1936 \\ AS A MANIFESTATION OF WORKING CULTURE IN THE \\ ARGENTINE INTERIOR
}

Mariana Mastrangelo*

\begin{abstract}
Resumen: En este trabajo se analizará la huelga del año 1936 en la ciudad de Río Cuarto, en el interior de la provincia de Córdoba, Argentina, y sus alcances y repercusiones como un claro ejemplo de cultura obrera. En el estudio de los sucesos de la huelga y en el desarrollo del movimiento obrero riocuartense podemos estudiar cómo se reveló esta cultura, que se caracterizó por la solidaridad como uno de sus rasgos distintivos. Encontramos que la Federación Obrera Local (FOL) fue la impulsora y promotora de involucrar a la sociedad y hacer que el sentido común de los huelguistas fuera compartido por el conjunto de la sociedad. La solidaridad también llevó a que las compañeras de los huelguistas se politizaran y conformaran los centros femeninos junto a las células del PC y la juventud comunista.
\end{abstract}

Palabras-clave: Cultura obrera, solidaridad, PC, pioneros, movimiento obrero.

* Doctora en historia (UBA 2010) y ha realizado un posdoctorado en la Universidade Federal de Santa Catarina (Brasil 2011). Es profesora de grado y de posgrado en la Universidad de Buenos Aires, Argentina. E-mail: mariana_mastrangelo@hotmail.com 


\begin{abstract}
This paper will discuss the strike of the year 1936 in the city of Río Cuarto, in the interior of the province of Córdoba, and its scope and impact as a clear example of labor culture. In the study of the events of the strike and the development of the labour movement riocuartense we can study how this culture, which was characterized by solidarity as one of its distinctive features are revealed. We find that the Local Workers Federation (FOL) was the initiator and promoter of society engaged and make that the common sense of the strikers was shared by the whole of society. Solidarity also led to the companions of the strikers is politicized and comprise the women's centers next to the cells of the PC and the Communist Youth.
\end{abstract}

Keywords: Labor culture, solidarity, PC, pioneers, labor movement.

\title{
Introducción
}

Raymond Williams definía a la tradición como una construcción que se basa en un principio de selección y que funciona como un mecanismo de incorporación, articulando procesos de identificación y de definición cultural, funcionando como un elemento formador del presente, ideando una versión del pasado creada deliberadamente para entablar lazos con el presente y ratificar sus significados y valores. Es nuestra intención en este trabajo reconstruir una tradición obrera e izquierdista (ambos conceptos se utilizaran indistintamente) del interior cordobés. Específicamente, nos centraremos en el estudio del movimiento obrero de la ciudad de Río Cuarto y en la huelga del año 1936 como ejemplos de esta cultura obrera. Esta cultura se rige por un principio radicalmente distinto a los de la clase dominante: este fundamento básico es la "solidaridad". La producción cultural de la clase obrera se caracteriza por su contribución específica a una herencia común más que por obras individuales. Solidaridad es uno de los rasgos distintivos que se aprecian en la huelga del año 1936 y en el conjunto del movimiento obrero riocuartense. Encontramos en este sentido que la Federación Obrera Local (FOL) fue la impulsora y promotora de involucrar a la sociedad y hacer que el sentido común de los huelguistas fuera compartido por el conjunto de la sociedad. La solidaridad también llevó a que las compañeras de los huelguistas se politizaran y conformaran los centros femeninos junto a las células del PC y la juventud comunista. De esta manera la cultura obrera se convertía en una forma de resistencia y lucha.

Este trabajo se estructurará a partir del análisis de dos ejes fundamentales: por un lado se abordarán los orígenes del movimiento obrero riocuartense, por el otro lado se analizará la huelga del año 1936 y sus repercusiones en la ciudad de Río Cuarto. Por último, delinearemos algunas consideraciones finales. 


\section{Orígenes del movimiento obrero riocuartense}

El informe de Bialet Massé de 1904 evidenciaba las duras condiciones en que trabajaban los obreros riocuartenses. Extensas jornadas de trabajo a cambio de salarios que no alcanzaban para la subsistencia, sin ningún tipo de asistencia social por parte del Estado. Si bien las condiciones en que trabajaban tanto los obreros urbanos y los obreros rurales riocuartenses eran tan malas como en el resto de la provincia de Córdoba, son notables porque lograron llamar la atención de este observador de la época. En su informe de 1904, Bialet Massé especificaba, por ejemplo, que los obreros riocuartenses trabajaban jornadas laborales de 11 a 12 horas por salarios mínimos. Sólo en el mercado los obreros gastaban un 40 por ciento de su jornal. En el informe se detallaban los distintos oficios y cuánto cobraban los obreros. Por ejemplo, las peores pagas eran las costureras y las sirvientas. Sin embargo, las costureras y las empleadas domésticas fueron las primeras que se organizaron y su sindicato aparece en los informes de la Federación Obrera Departamental del año 1936. ${ }^{1}$ Los otros oficios como panaderos, herreros, carpinteros, carreros, zapateros, talabarteros, empleados municipales también eran mal pagos y las jornadas eran largas. Al igual que las costureras y las empleadas domésticas, los obreros de estos oficios fueron los primeros en organizarse. Por ejemplo, los primeros sindicatos que surgieron en Río Cuarto fueron los de panaderos y carreros. También en el informe se encuentran talleres, destacándose el Ferrocarril Andino, donde la proporción de mano de obra extranjera era de 10 a 12 por ciento. Según Bialet Massé, los obreros de la construcción eran los mejores pagos ya que había pocos albañiles, teniendo los contratistas que traerlos de otras localidades. ${ }^{2}$ Esto demostraría la movilidad de los obreros riocuartenses, ya sea del campo a la ciudad a realizar trabajos en la construcción, como de la ciudad al campo para recoger la cosecha. De aquí provendría la denominación "siete oficio" de los obreros riocuartenses. La misma realidad, o quizás más dura, era la de los obreros rurales. Éstos se quejaban de las duras condiciones en que trabajaban y de lo desprotegidos que estaban. Por esta razón, en pueblos como Alejandro, Alcira Gigena, Elena, Coronel Baigorria, por mencionar a algunos de ellos, los conflictos de obreros rurales eran moneda corriente. El movimiento de los obreros rurales iniciado en toda la provincia de Córdoba en 1919-1921 se dejó sentir con fuerza en estas localidades, sobre todo los que se repitieron en el período 19351936. Se mencionan en el diario capitalino La Voz del Interior conflictos de estibadores y transportistas en toda la zona cercana a Río Cuarto por esta época. ${ }^{3}$ Asimismo, en las actas de la Federación Obrera Departamental, se encuentran cartas y pedidos de obreros rurales hacia la federación para que ésta mande delegados a mediar en los conflictos con la patronal. Es de señalar que la Federación Obrera Departamental en el año 1935 estaba dirigida por los comunistas. Éstos tuvieron un rol protagónico en la organización de los 
obreros rurales, que a partir del año 1936 se incorporaron a la misma. ${ }^{4}$

Estas duras condiciones laborales llevaron a que los trabajadores riocuartenses, en su mayoría inmigrantes, empezaran a organizarse, en un primer momento, en sociedades de socorros mutuos. Empero, estas sociedades no se mostraban proclives a reivindicaciones de clase ni a posturas contestatarias. Esto se debió a que combinaban distintos sectores sociales como empleados, pequeños industriales, profesionales y obreros. Sin embargo, en el año 1895 se dio la primera medida de lucha por reivindicaciones laborales en Río Cuarto que ha quedado registrada, siendo los obreros gráficos los que la iniciaron. En 1897 se estableció el Círculo Católico de Obreros. Y en 1903 se organizó el primer gremio de la ciudad, el de panaderos. En 1906 se conformó el Gremio de Vendedores de Carbón y Leña que realizaron en este año su primera huelga. También en ese año se creó el gremio Unión de Conductores y Carruajes. ${ }^{5}$ Es significativo remarcar que el nacimiento de las sociedades mutualistas en la ciudad de Río Cuarto fue contemporáneo a las de la ciudad capital de Córdoba. Lo mismo sucedió con la creación del Sindicato de los Panaderos y con los primeros conflictos obreros por reivindicaciones laborales. Esto revelaría una temprana organización mutualista y luego obrera y sindical de los trabajadores riocuartenses desde fines del siglo XIX. Si vinculamos esta temprana organización obrera con el surgimiento de las sociedades de socorros mutuos por nacionalidad y los grupos de discusión, éstas evidencian el surgimiento de prácticas colectivas. Combinadas con tradiciones radicales como el garibaldismo y con el crecimiento de la clase obrera en un contexto de sobreexplotación, éstas derivan en prácticas clasistas que van conformando una cultura obrera. Siguiendo a Williams, entendemos a la cultura como el análisis de un modo de vida, como una experiencia ordinaria que todos experimentamos y que transforma su sentido de época en época. Esa experiencia ordinaria el autor la denominó "comportamiento correcto", "sentido común" y "estructuras de sentimientos". 6

En el año 1916, el Partido Socialista (PS), junto a otras sociedades obreras, solicitaron el Teatro Municipal para celebrar el primer festejo del día del trabajador en esta ciudad. Según el diario local El Imparcial los actos fueron de "contornos nunca vistos", "con banderas rojas, el teatro estuvo repleto". En 1917, se celebró nuevamente el $1^{\circ}$ de mayo en la ciudad con la misma repercusión del año anterior. ${ }^{7}$ En el año 1918 se conformó el Sindicato de Obreros Ladrilleros, tras largos años de protagonizar jornadas en defensa de sus derechos. Pertenecían, junto a Albañiles y Anexos, a un mismo sindicato.

La multiplicación de gremios derivó en la creación, en 1919, de la Federación Obrera Local (F.O.L). Este año concluyó con una huelga general llevada a cabo por los obreros hombreadores y estibadores que reclamaban la jornada de ocho horas y mejores salarios. Se adhirieron a la huelga los molineros, barraqueros y personal de la Usina Eléctrica. La F.O.L. apoyó el 
movimiento de resistencia. Dos semanas después, se llegó a un acuerdo entre patrones y obreros. ${ }^{8}$

En 1923, los obreros panaderos, albañiles y municipales reclamaron también por la jornada de ocho horas y por aumento salarial. Este mismo año, en el mes de junio, se decretó una huelga general por todos los gremios pertenecientes a la F.O.L en protesta por el asesinato del anarquista Kurt Wilkens. Para hacer respetar la medida, los huelguistas mataron a un lechero que entraba en la madrugada a repartir leche quebrando la medida decretada. ${ }^{9}$ Este hecho es revelador de la nueva cultura ya que el movimiento obrero riocuartense aceptó esta ejecución porque no se registraron protestas o condenas por parte de las organizaciones obreras. Nuevamente en el año 1924 hubo protestas de los obreros, en este caso, por la Ley de Jubilaciones. ${ }^{10}$ En 1925 se fundó la Sociedad Unión de Obreros Municipales, caracterizándose éstos por su combatividad. El 30 de mayo de 1930 ésta presentó un petitorio al intendente Vicente Mojica, ${ }^{11}$ donde exigían el pago de los sueldos atrasados. Se realizó una huelga de 48 horas que paralizó la ciudad. Para solucionar el conflicto con los obreros municipales, el intendente debió vender al Banco de Italia y Río de la Plata un terreno céntrico. ${ }^{12}$

En el año 1935, el Partido Comunista (PC) se impuso en la dirección de la Federación Obrera Local, aunque compartía con el PS y obreros radicales las secretarias de la federación. Su secretario general fue José Cagnetta, militante de este partido. Hijo de campesinos sin tierra y corrido por el hambre, este obrero y militante llegó a Río Cuarto para trabajar en la construcción, que abarcaba en gran medida la principal fuente de trabajo para los hombres venidos de las zonas rurales. Cagnetta fue de los obreros que combinaron, sin descanso ni reparo, el trabajo agotador de la obra con la militancia política y sindical. Fue cofundador del Sindicato Único de la Construcción y de la Federación Obrera Departamental de Río Cuarto, también se desempeñó como delegado de la Unión Obrera Provincial. Cagnetta fue una de las figuras más importantes en la organización de la huelga de los obreros de la construcción del año 1936.

\section{La huelga del año 1936}

El 23 de octubre de 1935, el Sindicato de Albañiles de la Capital Federal, llamó a una huelga por demandas que incluían el reconocimiento del sindicato y de un delegado por obra. Adhirieron a la medida los oficios complementarios como frentistas, yeseros, parquetistas y pintores. Dos meses después, llamaron a un paro nacional, convocado por un Comité de Defensa y Solidaridad con los obreros de la construcción. El paro se hizo efectivo los días 7 y 8 de enero de 1936. En Buenos Aires, el acatamiento a la huelga fue total. Se paralizó el transporte, se produjeron choques con la policía y se 
crearon "zonas liberadas". ${ }^{13}$ La repercusión de estas jornadas se hizo sentir en todo el país. En el interior de la provincia de Córdoba, la huelga tuvo consecuencias importantes en la ciudad de Río Cuarto. Los obreros albañiles riocuartenses, haciéndose eco del conflicto en Buenos Aires, también comenzaron con medidas de protesta. Reclamaban por mejores salarios y pedían por la jornada de ocho horas, pero sobre todo, que se les reconociera el sindicato. El gremio de la construcción estaba dirigido en Río Cuarto por los dirigentes obreros y comunistas José Cagnetta y Eulogio Astrada. ${ }^{14} \mathrm{La}$ huelga, que tuvo un alcance nunca antes visto en Río Cuarto, contó con la solidaridad a nivel local de la Federación Obrera Local (F.O.L) y a nivel provincial de la Unión Obrera Provincial (U.O.P). Asimismo, los sectores populares riocuartense apoyaron a los obreros en huelga, en particular, la organización de la solidaridad provino de las mujeres de los huelguistas que se reunieron en el Centro Femenino. Éste, luego del conflicto, continúo funcionando, incorporándose a la Federación Obrera Departamental. ${ }^{15}$

La huelga de la construcción en Río Cuarto reveló una cultura obrera que puede rastrearse en el transcurso del conflicto. Esta se manifestó a través de la tradicional lucha por la reivindicación laboral, el reconocimiento del sindicato, la politización de los obreros de la construcción y la adhesión de la huelga por parte de los sectores populares riocuartense. En este sentido, el nivel de adhesión a la huelga es el dato distintivo para analizar ya que la misma se puede deber a las formas de organización del paro o a la sensación de impotencia ante la explotación patronal. Pero esto no alcanza para explicar la solidaridad ante la huelga, ya que niveles altos de explotación no garantizan medidas de fuerza, y la organización tampoco lleva a una adhesión masiva más allá de los huelguistas y sus familias. La pregunta aquí debería ser porqué el conflicto se da en ese momento, con esa virulencia y con ese alto nivel de solidaridad. Si bien la organización y la explotación aportan pistas para el análisis, por si solos no alcanzan. Con la difusión de conceptos clasistas, de una fuerte "conciencia en si" es que la "lucha de uno" puede ser vivenciada como la "lucha de todos". En este sentido, la experiencia clasista de la explotación se traduce en una "estructura de sentimiento" que le da sentido en el corazón y las mentes de la clase obrera. Este conjunto de conceptos es vivenciado como sensaciones de injusticia, de solidaridad que define el "nosotros versus ellos". De esta manera, se convirtió una huelga sectorial en un conflicto generalizado que permite vislumbrar aspectos de la conciencia obrera y sobre todo la cultura clasista o izquierdista. Así se conforma lo que une a individuos en una clase social a través de patrones comunes de conducta que traducen las relaciones sociales de producción en algo más que una noción abstracta y lo convierte en algo vivencial. Esta transformación en la toma de conciencia de los obreros riocuartenses tuvo lugar a lo largo del transcurso de la lucha reivindicativa de la huelga de 1936. 
El conflicto en Río Cuarto comenzó el día 7 de enero de 1936. El problema central era que se pagaban bajos salarios y se daban vales como forma de pago. A su vez, los constructores, agrupados en el Centro de Constructores, no aceptaban el pliego de condiciones presentado por el Sindicato de Albañiles y Anexos. En el mismo se remarcaba como primer punto, el reconocimiento del sindicato, luego se exigían mejoras salariales y que se cumpliera la jornada de 8 horas.

El día 8 de enero, llegaban a Río Cuarto las sangrientas noticias sobre el enfrentamiento entre obreros de la construcción y la policía en Buenos Aires. El estallido de la huelga de albañiles en Buenos Aires había dejado como saldo negativo a 6 muertos y más de 50 heridos tras el enfrentamiento entre la policía y los huelguistas. Sesenta sindicatos de todo el país se solidarizaron con los huelguistas porteños, llamando a un paro total de actividades. El día 9 de enero, en Buenos Aires, a las cuatro horas de la tarde se levantó la huelga general. ${ }^{16}$

Estas noticias rápidamente tuvieron repercusión en Córdoba y especialmente en Río Cuarto. En la ciudad capital, la U.O.P sacó un comunicado el día 9 de enero donde solicitaba que todas las centrales obreras llamaran a asambleas extraordinarias para hacer llegar solidaridad a los obreros en huelga y que estuvieran preparados "para un llamado a un paro general". ${ }^{17} \mathrm{En}$ Río Cuarto se esperaban con inquietud las noticias de los acontecimientos en Buenos Aires. Esto queda evidenciado en una carta escrita por José Cagnetta a su amigo y dirigente gráfico y socialista Andrés Lassizuch:

"Esperábamos con ansiedad el desarrollo de los acontecimientos que iban produciéndose en Buenos Aires. Los dirigentes del gremio de la construcción habían dispuesto a la gente a lo que viniera ya que la situación no podía seguir siendo la misma después de los fracasos por la intransigencia de los dirigentes de la F.O.R.A. y de la patronal de la construcción". ${ }^{18}$

Nótese en el testimonio cómo el dirigente comunista señala amargamente el accionar de la F.O.R.A. V Congreso (anarquista) y el de la patronal de la construcción. De esta manera, siguiendo a los obreros de Buenos Aires, los trabajadores riocuartenses se organizaron en la lucha por sus derechos laborales. Y los mismos acontecimientos se fueron precipitando. El día 14 de enero el conflicto con los obreros albañiles en Río Cuarto llegó a un punto álgido de tensión. Los Constructores se negaban a reconocer el Sindicato de Obreros Albañiles y Anexos y llamaban a que se reincorporaran al trabajo con mínimas mejoras salariales, con la total intención de desprestigiar la entidad gremial. ${ }^{19} \mathrm{~A}$ su vez, la huelga se hacía sentir entre los obreros mosaístas y frentistas. El Sindicato de Obreros Mosaístas y Anexos de Río 
Cuarto denunciaba un conflicto entre el gremio y la firma Moreno y Cía. Hacía 36 días que estos obreros estaban en huelga.

Asimismo, el Sindicato Obreros Albañiles y Anexos de Río Cuarto llamaban la atención sobre algunos patrones de la construcción ${ }^{20}$ que estaban reclutando mano de obra como rompehuelgas. El sindicato pedía a los obreros que "no cayeran en la tentación." 21 El pedido del sindicato implicaría la existencia de rompehuelgas que estaban dispuestos a fragmentar la solidaridad con los huelguistas.

Mientras tanto, los distintos gremios obreros de Río Cuarto se aprestaban a realizar un paro de 48 horas en adhesión a los obreros albañiles. El día 16 de enero el Sindicato de Obreros de la Construcción rechazó el arbitraje del Departamento de Trabajo. El Centro de Constructores, ante la respuesta de los huelguistas envió una carta a la F.O.L., invitándolos a una reunión para llegar a un acuerdo. En esa reunión no se llegó a ninguna solución. ${ }^{22}$ El día18 de enero el conflicto entre Constructores y obreros albañiles en Río Cuarto entró en su faz decisiva. El Centro de Constructores desconoció el derecho sindical que asistía a los obreros. Los obreros albañiles y dirigentes del gremio de la construcción que estaban al frente de la lucha, José Cagnetta y Eulogio Astrada, decidieron, junto al comité de huelga, seguir con las medidas de fuerza. ${ }^{23}$

El día 19 de enero, el Centro de Constructores envió una carta a la F.O.L. en donde manifestaba que aceptaba el pliego de condiciones, pero con modificaciones en relación al trabajo nocturno y que se regirían con el reglamento aceptado en la Capital Federal. ${ }^{24}$ Ese mismo día, la F.O.L le respondió por carta al Centro de Constructores, que no habiéndose resuelto el conflicto en la Capital Federal, la federación consideraba que de esta manera no se reconocía el pliego de condiciones presentado. Por resolución de asamblea general, se había decidido ir a una huelga general los días 21 y 22 de enero. ${ }^{25}$

Los días 21 y 22 de enero habían transcurrido de la siguiente manera, según la crónica de un corresponsal del diario La Voz del Interior que había sido enviado para cubrir el conflicto:

"En el mayor orden se desarrolló la huelga decretada por la Federación Obrera de Río Cuarto. En solidaridad con los obreros albañiles, la ciudad quedó paralizada, hasta el diario local no salió ayer. A la tarde se realizó un mitin, donde habló el representante de la Federación Obrera Local, señor Marcelino Reynoso. ${ }^{26}$

El llamado a un paro general por parte de la Federación Obrera Local y el acatamiento del mismo, donde "la ciudad quedó paralizada", daría cuenta de la trascendencia que el conflicto de los obreros de la construcción llegó a 
tener en Río Cuarto. Habría que señalar el rol protagónico que tuvo el PC en la organización de la huelga, a través de la Federación Obrera Local. Aunque debe mencionarse que la federación obrera riocuartense, si bien estaba dirigida por miembros del PC, en la misma también convergían socialistas, anarquistas y radicales, que estaban comprometidos con el desarrollo de la huelga. Fueron obreros y militantes de distintos partidos pero que compartían prácticas clasistas comunes, como José Cagnetta, Eulogio Astrada, el mismo Marcelino Reynoso ${ }^{27}$ citado en la crónica del diario capitalino La Voz del Interior, los que se destacaron en todos los acontecimientos de la huelga por su empeño en organizar a los obreros. De nuevo aquí, como en la huelga del año 1929 en San Francisco, el reconocimiento del sindicato fue el punto de inflexión en las negociaciones con la patronal. ${ }^{28}$ Esta fue la batalla más importante librada por la Federación Obrera Local y por el PC en el conflicto de los obreros de la construcción.

A su vez, la huelga de la construcción fue el disparador de otros conflictos. El día 25 de enero el Sindicato de Estibadores de Río Cuarto decretó una huelga por tiempo indeterminado. ${ }^{29}$ Se reclamaba por aumento de salario, la jornada de ocho horas y que se reconociera al delegado sindical, entre las condiciones más importantes. Se remarcaba que los obreros debían ser designados por el sindicato. Entre uno de los artículos del pliego de condiciones se pedía que el trabajo se hiciera a un ritmo "humano", no corriendo y cargando bolsas de 50 o más de kilos. ${ }^{30}$

También, los obreros del Molino Eminco presentaron el 4 de febrero un pliego de condiciones donde lo primero que se pedía era el reconocimiento del delegado y del sindicato, que estaba dirigido por el PC. Luego el pliego continuaba con una lista que estipulaba un aumento de salario para cada rubro. Además, la jornada de ocho horas, el sábado inglés pago y se especificaba que no se trabajaría el $1^{\circ}$ de mayo. ${ }^{31}$

Sin miras de solucionarse el conflicto de los obreros de la construcción, el día 11 de abril, junto a todos los gremios agrupados en la F.O.L., le enviaron una carta al gobernador electo Amadeo Sabattini. En la misma se le informaba sobre la dura situación que estaban viviendo los obreros riocuartenses por la intransigencia del Centro de la Construcción en reconocer el pliego de condiciones. Le solicitaban a Sabattini que les diera valor a las organizaciones obreras locales para que se encargaran de velar por el cumplimiento de las leyes obreras. Pedían que los inspectores del Departamento de Trabajo fueran de Río Cuarto, y que la F.O.L. pudiera elegir uno de ellos para que el conflicto se solucionara. ${ }^{32}$ El día 28 de mayo el Centro de Constructores tuvo que llegar a un acuerdo con los obreros en huelga, respetando el pliego de condiciones presentado por la F.O.L, ${ }^{33}$ poniendo fin al conflicto luego de dos meses y medio donde se evidenció una cohesión notable entre los obreros.

A su vez, en el mes de mayo de este año, se realizó una Conferencia 
Nacional de Trabajadores de la Construcción en la Capital Federal. En la misma participaron 62 delegados pertenecientes a 61 organizaciones de trabajadores de la industria de la construcción. De este encuentro surgió una Comisión provisoria que tenía como objetivo llamar a un Congreso Constituyente de la Federación Nacional de la Construcción (F.O.N.C.) para confeccionar un convenio que estableciera las pautas mínimas de carácter económico y social para el obrero de la construcción. Asimismo, se buscaba reunir en un sindicato único a todos los gremios de la construcción. Había sido designado, como delegado por Córdoba, Rufino Gómez, obrero de la construcción y uno de los miembros más renombrados del PC cordobés. Meses después, en octubre, se creó el Sindicato Único de la Construcción de Río Cuarto.

De esta manera, la huelga de los obreros de la construcción consiguió, por intermedio de la labor que llevó adelante la F.O.L., el PC, y sobre todo, la solidaridad y la persistencia en la lucha de los huelguistas, que se reconocieran sus reclamos laborales. Tras la represión, el conflicto terminó con un triunfo parcial. La agremiación aumentó como consecuencia de algo que era visto como una victoria, el aumento de salario obtenido tras la intervención del Departamento Provincial del Trabajo. A pesar de que los empresarios constructores no quisieron reconocer al sindicato, no tuvieron más remedio que negociar con los huelguistas. Es de señalar que el reconocimiento del sindicato fue el elemento más significativo en la lucha que llevaron adelante los obreros albañiles por más de tres meses. A partir de esta huelga, el 12 de octubre de 1936, se fundó el gremio de la construcción en Río Cuarto. Como balance del conflicto, el obrero de la construcción Víctor Barrios recordaba que el mismo tuvo éxito por la metodología que utilizaron los obreros albañiles. Se destacaron dos elementos nuevos en la ciudad de Río Cuarto, según relató el entrevistado. En primer lugar, la solidaridad de los obreros huelguistas y el conjunto de los trabajadores riocuartenses. Éstos habían ideado una suerte de bonos solidarios de los huelguistas que recorrían las ciudades, los pueblos, concentraciones, comedores escolares. En los barrios populares como Banda Norte y Alberdi, lugares de donde provenían la mayoría de los obreros albañiles, las panaderías donaban el pan y los lecheros la leche para los huelguistas y sus familias. Esta idea de abrir comedores y los bonos solidarios para los obreros en huelga y sus familias, la había tenido el dirigente comunista Miguel Burgas, quien por esos años se desempeñaba como obrero albañil en la Capital Federal. Para mantener la huelga y su organización, según planteaba Burgas, era necesario convencer a comerciantes, almaceneros, panaderos y verduleros para que se comprometieran con los obreros en huelga, quienes eran sus principales compradores. De esta manera, con la ayuda de éstos se pudieron abrir comedores en Capital Federal. De este ejemplo se valieron los obreros riocuartenses quienes reprodujeron comedores y bonos solidarios para los huelguistas en la ciudad de Río Cuarto. ${ }^{34}$ Las mujeres de 
los huelguistas eran las encargadas, junto a la F.O.L, de organizar las colectas y luego de repartirlas. Éstas, a partir del conflicto, se organizaron en el Centro Femenino, que siguió funcionando luego de terminada la huelga. Asimismo, la solidaridad de las demás organizaciones obreras, tanto a nivel provincial con la U.O.P. y a nivel nacional, con el apoyo de la C.G.T., ayudó a mantener el conflicto. También, el abogado radical Miguel A. Zabala Ortiz, mediante una carta enviada a la Federación Obrera Local se solidarizaba con los obreros de la construcción en huelga y ofrecía sus servicios profesionales. ${ }^{35}$ En segundo lugar, la huelga de los obreros de la construcción, según Barrios, tomó carácter nacional. Se luchaba contra los grandes monopolios, nacionales y extranjeros. En la ciudad de Río Cuarto, los obreros albañiles se enfrentaban a los grandes empleadores de la construcción, que estaban organizados en el Centro de Constructores. La respuesta de la patronal fue agresiva y represiva. Ante la magnitud del conflicto, los empresarios de la construcción utilizaron todas sus influencias para que la policía persiguiera y detuviera a los obreros en huelga. Según Barrios, su consigna era "vencer a los huelguistas y destrozar sus organizaciones gremiales". ${ }^{36}$

\section{La constitución del Sindicato Único de la Construcción en Río Cuarto}

Luego del conflicto que tuvieron los obreros albañiles riocuartenses con el Centro de Constructores de esta ciudad, el 12 de octubre de 1936 y como consecuencia de la Conferencia Nacional de Trabajadores de la Construcción en la Capital Federal en el mes de mayo de ese mismo año, se constituyó el Sindicato Único de la Construcción de Río Cuarto. Durante muchos años este gremio fue el más numeroso por las actividades que abarcaba. En su seno confluían pintores, madereros, yeseros, mosaístas, vidrieros, cloaquistas, hojalateros, ladrilleros, frentistas y otras actividades anexas. Entre los obreros que se destacaban estaba José Cagnetta, Servando Romero, Eulogio Astrada, Isidro Flores, Daniel Olmedo, Faustino Pulmonares, todos militantes comunistas. Es de remarcar que este sindicato fue uno de los impulsores de la organización de todo el sindicalismo riocuartense. La constitución del sindicato fue llevada a cabo con la presencia de cien obreros albañiles y la misma fue presidida por el obrero Servando Romero. El primer secretario nombrado fue Ernesto Biassi. Entre los temas que se discutieron en esa primera asamblea fue la presentación de un pliego de condiciones laborales que iba a presentarse al Centro de Constructores. También se solicitó una colaboración para los obreros ladrilleros que estaban en conflicto con sus empleadores. Además se leyó una carta enviada por la recién constituida Federación Obrera Nacional de la Construcción (F.O.N.C) que también pedían una contribución en dinero para los trabajadores españoles republicanos que luchaban contra el fascismo. ${ }^{37}$

Uno de los gremios en donde el PC tuvo un activismo importante 
era en la construcción, sobre todo a partir de mediados de la década de 1930 . El principal sector de la construcción fue el de los albañiles que incluía a un pequeño número de obreros calificados y a una masa de personas que utilizaba este trabajo como entrada al mundo urbano. Asimismo, esto se vio reforzado en la década de 1930 por la gestión del intendente radical Emilio Jautz (1936-1939). Su objetivo era activar la economía y combatir el desempleo por medio de la realización de obras públicas como pavimentación, cloacas, distribución de agua corriente y edificios públicos. Esto se combinó con un progresivo desplazamiento de agricultores ricos hacia la ciudad, que construyeron viviendas nuevas y también comercios. Este movimiento generó una constante demanda de mano de obra.

Río Cuarto era un reflejo de lo que sucedía a nivel nacional.Acomienzos de la década de 1930, en la Capital Federal, el sindicato de los albañiles incluía a comunistas, cada vez más influyentes, y a los antiguos anarquistas y sindicalistas, fundadores éstos del gremio en 1890. Los comunistas lograron imponer, en 1934, a sus dirigentes en la conducción del gremio, como Guido Fioravanti, Ángel Ortelli y Miguel Burgas. Siendo separados por los anarquistas, fundaron a comienzos de 1935 una entidad propia: el Sindicato de Obreros Albañiles, Cemento Armado y Anexos. (Luego cambio el nombre por Sindicato Único de Obreros de la Construcción SUOConstr.) En 1936, junto a numerosos sindicatos del interior, se conformó la Federación Obrera Nacional de la Construcción (F.O.N.C), de predominancia comunista. ${ }^{38}$ En la ciudad de Río Cuarto, la influencia del PC en la constitución del sindicato en esta ciudad fue fundamental. Como recordaba el obrero de la construcción Víctor Barrios:

\footnotetext{
"Obreros de la construcción como Pulmonares, Flores y Cagnetta, habían sido verdaderos líderes comunistas y dirigentes obreros de gran peso. Ellos contribuyeron a la formación de las primeras organizaciones obreras y federaciones, acá en la zona. La Federación Obrera Local y la Federación Departamental de Trabajadores, fueron protagonistas de este movimiento. Es decir, los comunistas eran los líderes natos, de esa tendencia de lucha de clase que se originó aquí en Río Cuarto. Y eso le dio valía al Partido Comunista". ${ }^{39}$
}

\section{La Federación Obrera Departamental}

Existe un libro de Actas de la Federación Obrera Departamental que se inició el 21 de junio de 1936 y se terminó el 19 de agosto de 1950. José Cagnetta conservó este libro de actas y también fue el encargado de reunir y armar un archivo del Sindicato Único de la Construcción de Río Cuarto. A finales de la década de 1930, Cagnetta, por razones de salud, se 
retiró de la federación y del mismo sindicato de la construcción. El archivo de la federación y del sindicato de la construcción pasó a manos de Víctor Barrios, que durante décadas lo siguió alimentando y lo preservó para que no se perdiera, hasta el día de su muerte. ${ }^{40} \mathrm{El}$ archivo de la Federación Obrera cuenta con un rico acervo documental como por ejemplo, documentos de la huelga del año 1936, el libro de actas de la federación, cartas, telegramas, informes de la U.O.P., del Comité Pro Unidad Obrera, invitaciones a actos, mítines, conferencias, pedidos de solidaridad y también bailes. También se encuentran volantes y folletos de la F.O.L., del PS y del PC.

A raíz de la huelga de la construcción en Río Cuarto, además de que se conformó el Sindicato Único de la Construcción en esta ciudad, la Federación Obrera Local pasó a denominarse Federación Obrera Departamental de los Trabajadores de Río Cuarto, por decisión plenaria de todos los sindicatos de la ciudad. ${ }^{41}$ Existían para esta época en Río Cuarto, según el censo de la Federación Obrera Departamental de Trabajadores, el Centro Empleados de Comercio, el Sindicato Único de la Construcción, la Unión Obreros Municipales, el Sindicato de Molineros y Anexos, el Sindicato de Estibadores, Panaderos, Sastres, Gráficos, Canillitas, Metalúrgico, Ladrilleros, Chauffers. Se mencionaban también los sindicatos rurales de Alejandro, Elena, Coronel Baigorria, Adelia María, General Cabrera, Berrotarán, Alcira Gigena y casi todos los pueblos de la región sur. ${ }^{42}$ Fueron designados para ejercer el consejo de la Federación Departamental Ernesto Biassi, José Cagnetta, Miguel Navarro, Víctor Sánchez, Juan Cedriani, Servando Romero, Juan Flores y Eulogio Astrada. Con la excepción de Juan Cedriani que era sastre (socialista) y Víctor Sánchez que era carpintero (no se sabe su adscripción partidaria), el resto eran obreros de la construcción y militantes del PC.

Tras tres meses de huelga de obreros de la construcción, el acto del $1^{\circ}$ de mayo del año 1936 fue sentido como la culminación de un movimiento reivindicativo y de lucha de todos los trabajadores riocuartenses. La Federación Obrera como organizadora de este evento invitó al PC y al PS a participar del mismo. Hay que recordar que el $1^{\circ}$ de mayo todavía no era reconocido oficialmente como un día no laborable. Por esta razón, se conformó un comité de huelga que se ocupó de que el día de los trabajadores se llevara a cabo. La primera convocatoria del comité de huelga decía:

"Próximo ya el $1^{\circ}$ de mayo, el comité de la Federación Departamental de Trabajadores se dirige a los sindicatos y agrupaciones adheridas para hacerle llegar el último llamado a fin de que dispongan desplegar al máximo de actividades para que el día de los trabajadores adquiera este año una importancia desconocida hasta ahora. A ese efecto, las comisiones directivas deben convocar a los afiliados a asamblea general el jueves 30 a la noche a objeto 
de tomar conocimiento de las siguientes resoluciones de la junta ejecutiva: 1) los núcleos de agitación que se han constituido deben vigilar, siendo la comisión de huelga la que debía mantener el contacto. Deberán visitar las casas de los compañeros sindicalizados o no invitándolos a la gran manifestación de la tarde. Especialmente deberán invitarse a las mujeres para que haya una columna con ellas. 2) Debe comunicarse en todos los hogares que el $1^{\circ}$ de mayo habrá una matiné a las 13 horas en el Cine Renacimiento para los niños y una velada a la noche para los mayores a la noche (sic.). Es preciso ensayar canciones que han sido distribuidas para ser cantadas en las manifestaciones. No debe haber gritos a favor ni en contra de ningún partido político. El secretario del comité de huelga terminará su discurso diciendo: ¡Trabajadores de Río Cuarto, por la libertad, contra el fascismo! ¡Contra la explotación del hombre por el hombre!"43

Nótese en el documento emitido por la federación obrera, en primer lugar, el nivel de organización de la misma. Antes que nada, el llamado a los afiliados a asamblea general para que tuvieran conocimiento de las resoluciones del comité de huelga. Los núcleos de agitación que se habían formado deberían vigilar las zonas, mantener contactos con la comisión de huelga y visitar a "todos" los compañeros sindicalizados para que asistieran con sus familias al acto. En segundo lugar, el interés por mantener el esfuerzo unitario de los trabajadores riocuartenses, solicitando que no hubiera gritos a favor ni en contra de ningún partido político. En tercer lugar, el trabajo de masas, invitando a las mujeres a participar de una columna especial, realizando actividades culturales y recreativas para las familias de los trabajadores con una matinée para los niños y una velada a la noche para los adultos. Por último, la radicalización de la federación obrera imponiendo al secretario del comité de huelga la consigna final de su discurso.

Del acto participó el delegado del Comité Pro Unidad Obrera, el dirigente comunista José Manzanelli. Estuvieron también presentes el PS y el PC. Éste último mandó una carta a la Federación Obrera Departamental para sumar su participación en el acto. En la carta aceptaban, el partido y la Juventud Comunista, la invitación de la Federación Obrera Departamental. El PC se había reunido con el PS para hacer un acto conjunto. Dado que la Federación Obrera Departamental invitó a todas las organizaciones y sindicatos obreros de la ciudad, como también a los partidos de izquierda para hacer un único festejo, estos últimos se incorporaron a la organización. El PC mandó como delegados a la reunión del comité de huelga a los camaradas Blas Suárez, Alberto Castañeda y José Cagnetta. ${ }^{44}$ Como recuerda Barrios, el festejo de ese $1^{\circ}$ de mayo se destacó por: 
"El colorido de sus vestimentas que se mezclaba con banderas azules, blancas y rojas. Todos ellos marchaban encolumnados y acompañados de música y canciones que ejecutaba Don Pierino Rosos, alternativamente El Himno Nacional, La Marsellesa, Hijos del Pueblo y la Internacional" ${ }^{45}$

Nuevamente en este testimonio la noción de cultura izquierdista se hace presente. A la organización y radicalización del acto del $1^{\circ}$ de mayo del año 1936, se le pueden añadir las prácticas culturales izquierdistas de los obreros riocuartenses que quedarían representados en el relato. Sin distinciones políticas ni ideológicas, se mezclaban ese día las banderas azules, blancas y rojas, junto a las melodías de los himnos que entonaban. Se hacían presente, bajo las órdenes del director de orquesta Don Pierino Rosos, El Himno Nacional, La Marsellesa, Hijos del Pueblo y la Internacional. Es interesante que en Río Cuarto se cantara la Marsellesa que aun retenía su característica revolucionaria brindada por el radicalismo artesanal de los sans-culottes de 1789.

El día 19 de julio del año 1936, organizado por la F.O.L., se realizó un congreso donde participaron la totalidad de los sindicatos locales. El congreso adhirió al Comité Pro Unidad Obrera, "única sede del sindicalismo provincial" como decía Miguel Contreras. ${ }^{46}$ Nacía así un ámbito cada vez más amplio para dirimir los conflictos que se sucedían. Un ejemplo del dinamismo organizativo y de la campaña de agremiación de la época sería el siguiente volante subscripto por la F.O.L., éste decía:

“Compañeros, para destruir la organización, maniobras patronales, presión policial, cierre de locales, desconfianza hacia la dirección, cizaña y no colaboración. Compañeros, contra éstas y otras lacras, a trabajar bajo el único grito

¡Viva la organización, Adelante. Siempre la clase trabajadora! ${ }^{47}$

En este plenario, la F.O.L. resolvió también cambiar de denominación por la de la Federación Obrera Departamental de Trabajadores de Río Cuarto, a raíz de la incorporación de nuevos gremios y la ampliación geográfica ya que se sumaron los sindicatos rurales de la zona sur. La federación se adhirió a su vez a la Confederación General del Trabajo (C.G.T) y su principal reivindicación fue que se cumpliera la jornada máxima semanal de 40 horas y vacaciones anuales pagas. ${ }^{48}$ Cuando se constituyó la Federación Departamental de Trabajadores, se produjo la siguiente declaración: 
"Se convoca al proletariado a estrechar filas en torno a la lucha reivindicativa ya que esa es la forma en que la clase trabajadora puede enfrentar el reclamo con éxito ante los amagos de la reacción, y reconoce en la C.G.T. la coincidencia en enfrentar los múltiples problemas de los trabajadores, entre los cuales se cuentan las ocho horas de trabajo". ${ }^{9}$

El cambio en la denominación de la Federación Obrera y la incorporación de nuevos gremios de la ciudad y de las zonas rurales daría cuenta de un crecimiento importante del movimiento obrero y sindical en la ciudad de Río Cuarto. Esto sería producto de los meses de lucha que llevaron adelante los obreros de la construcción para que se les reconociera el sindicato. De allí que meses más tarde se conformara el Sindicato Único de la Construcción y que la Federación Obrera creciera cuantitativamente en el número de afiliaciones y en los sindicatos que se incorporaron. Fruto de la politización y el crecimiento sindical de los obreros en Río Cuarto fue el gran acto que realizó el Sindicato Único de la Construcción de esta ciudad en repudio a la ley de Matías Sánchez Sorondo contra el comunismo. Del mitin participaron los partidos de izquierda de la ciudad, la UCR y la Federación Obrera Departamental. ${ }^{50}$

De esta manera, la Federación tomó gran impulso en toda la región a partir del año 1936. El crecimiento en la organización obrera también significó el desarrollo de la izquierda, en particular el PC. A partir de este año se terminaron de organizar los sindicatos obreros en toda la zona sur de la provincia, y la Federación fue la protagonista de todo ese movimiento. En cada pueblo, aparte del sindicato, se organizaba también el PC, la Juventud Comunista y los Centros Femeninos. Cómo recuerda Barrios, viajaban delegados a Alejandro, La Carlota, Bengolea, Sampacho, Adelia María, Laboulaye o Huanchilla a "atender problemas y conflictos entre obreros y patrones". Por ejemplo, el 20 de febrero de 1938, el delegado del Sindicato de Albañiles y Anexos y militante del PC, Eulogio Astrada, reseño en un informe toda la labor de la Federación Obrera Departamental:

"Se ha producido en Alejandro un conflicto con los patrones. Se ha mandado un delegado al mitin organizado por el Sindicato de Oficios Varios de esta ciudad. También se mandó un delegado a Adelia María por un conflicto agrario. En Bengolea, se ha mandado delegado en dos oportunidades para ayudar a los conductores de carros. Envío de un delegado a Laboulaye por huelga de camioneros, mozos y obreros de la construcción. Intervención del consejo de la Federación en Adelia 
María por la detención de cuatro compañeros por asuntos políticos". ${ }^{51}$

El archivo de la Federación Obrera también cuenta con numerosos documentos que comprueban la constante actividad y el intercambio de correspondencia con otros departamentos como Juárez Celman, General Roca, Roque Sáenz Peña y Calamuchita. En estos departamentos era continuo también el envío de delegados de un lado a otro por los innumerables problemas que existían. Esto es notable dado que no tenían activistas rentados a tiempo completo ni presupuesto significativo.

El despliegue que alcanzó la Federación fue fuente de preocupación de los mismos delegados que la conformaban. El delegado por el Sindicato de Gráficos y militante socialista, Andrés Lassizuch, solicitó un mayor interés para la formación de cuadros sindicales por la multiplicidad de trabajo que tenía la Federación y además hacía consideraciones sobre la labor desplegada por la misma, que auxiliaba a los compañeros de la ciudad y de la región.52 Por ejemplo, en una carta que le envió a su compañero José Cagnetta que estaba en Río de los Sauces53 recuperándose de problemas de salud. Lassizuch decía:

"En los momentos actuales que estamos viviendo no alcanzan los hombres para colaborar en los muchos conflictos derivados de la situación agrícola en que llegan a diario pedidos de delegado por ejemplo, en la campaña; uno para el precio de la cosecha, otro para las maquinas trilladoras, para los estibadores, ayudantes, camioneros, etc. Así tratamos de atender solicitudes de Cabrera, Gigena, Alejandro, Moldes y nos vemos en figurillas para dar abasto a todos ellos. Y a propósito de Adelia María se plantearon tan graves los problemas allí que a último momento resolví yo, a falta de compañeros que pudieran trasladarse, hacerme cargo del problema y viajar a esa ciudad". ${ }^{4}$

Otro de los problemas recurrentes que aparecen en las actas de la Federación era el de la desocupación. Al igual que en toda la provincia de Córdoba, las sequías consecutivas en la década de 1930 había dejado a muchas familias sin trabajo. El registro habilitado por la Federación Obrera Departamental acusaba, para esa época, 500 obreros inscriptos, auténticos desocupados. A raíz del problema de la desocupación, la Federación envió un manifiesto al gobierno municipal y provincial que decía:

"La desocupación hace estragos y el nivel de vida de las clases populares ha creado múltiples problemas y cuya agudización paulatina provocará graves consecuencias, 
como ya lo es el delito o el pedido de limosna que ya suma a centenares de hombres, mujeres y niños... Por esta razón es que anhelamos que la Municipalidad de Río Cuarto cree trabajo para nuestros brazos, analizando con sentido humanitario nuestro pedido, nos permitimos elevar la resolución dada por la asamblea de desocupados". ${ }^{55}$

Es significativo que la Federación Obrera Departamental se dirigiera directamente a la Municipalidad de Río Cuarto y al mismo Gobierno Provincial para hacer su reclamo. Lo mismo había sucedido con la carta que envió la Federación al electo gobernador Amadeo Sabattini, donde le informaban sobre el desenvolvimiento de la huelga de la construcción del año 1936. Recordemos que en la carta enviada a Sabattini se le requería que la Federación pudiera elegir un delegado para mediar en el conflicto de los obreros de la construcción. De esta manera la Federación Obrera Departamental de Río Cuarto buscaba convertirse en un interlocutor válido entre la clase obrera y el Estado.

En el archivo de la Federación se encuentra también documentación referida al problema de la asistencia social de los trabajadores riocuartenses. Aunque en su mayoría estos programas de asistencia social se pusieron en práctica con posterioridad a 1943 y se los identifica con el peronismo, constituyeron, en rigor, una aspiración permanente del movimiento obrero desde sus primeras épocas. Temas como la salud, la educación y el esparcimiento de los trabajadores riocuartenses están contemplados en las actas de la Federación Obrera Departamental. Con respecto al interés por la salud de los obreros, en las actas se hallan una serie de documentos en torno a la discusión por la creación de un centro de salud. Tras largas tratativas, en el año1938 se inauguró un centro médico gratuito para los trabajadores. Conjuntamente, se pusieron en funcionamiento las Cajas Mutuales de cada sindicato. De esta manera se unía la atención médica con la ayuda económica para el obrero en caso de enfermedad. ${ }^{56}$ Asimismo, en relación a la educación, entre los miembros de la Federación, sobre todo entre los obreros gráficos, existía la inquietud de hacer una biblioteca para los trabajadores. Fue así que se solicitó a las autoridades provinciales un subsidio para la creación de la biblioteca. Junto a una colecta que realizó la Federación, se fundó en el año 1938 la Biblioteca Obrera Departamental. ${ }^{57}$ También, se discutía la necesidad de crear un periódico de la Federación. Se distribuía en esa época el periódico C.G.T., aunque era preciso, entre los gremios de la ciudad, tener un órgano de prensa propio. Este objetivo no llegó a concretarse en los años que funcionó la Federación Obrera Departamental. El esparcimiento también estaba presente en las Actas de la Federación. Cartas con pedidos de los distintos gremios como Metalúrgicos, el Centro Femenino, Madereros, Albañiles, Sastres, Gráficos, para hacer bailes en el local de la Federación. Estos bailes 
solían ser, en general, solidarios o a beneficio de alguna causa obrera. Por ejemplo, la Federación Obrera Ferroviaria le pidió a la Federación Obrera Departamental que realizara un acto en solidaridad por los presos políticos de Bragado. El acto solidario se realizó, junto a un baile a beneficio de los presos. ${ }^{58}$ Asimismo músicos conocidos en la ciudad como el italiano SeveroVietri se ofrecían para hacer espectáculos musicales, donde lo recaudado se destinaba a la Federación. ${ }^{59}$ De la misma manera, el local de la Federación Obrera Departamental era pedido para realizar reuniones y para proyectar películas con posteriores debates, por parte del Socorro Rojo Internacional. ${ }^{60}$ Lo mismo se puede decir del Comité Pro Ayuda al Pueblo Español, que solicitaba el local de la Federación para reunirse, realizar bailes en beneficio del pueblo español y también usaba de depósito el local de la Federación para los víveres y ropas recaudadas para mandar a España. ${ }^{61}$

\section{Consideraciones finales}

La huelga de los obreros de la construcción del año 1936 en la ciudad de Río Cuarto evidenció el accionar del PC y su capacidad organizativa que permitió una amalgama de intereses comunes, asentada en una cultura obrera ya existente. La misma puede indagarse desde fines del siglo XIX, con la llegada de los inmigrantes, que traían, algunos de ellos, ideas progresistas. Esta cultura se manifestó de distintas maneras a través de estos años: en las sociedades de socorros mutuos, en los grupos de discusión, en las primeras bibliotecas, los primeros sindicatos y la presencia de partidos de izquierda. Estas instituciones realizaban, a su vez, actividades educativas y culturales como proyección de películas con temáticas referidas a los trabajadores, ${ }^{62}$ charlas debates, obras de teatro, conferencias y bailes que se realizaban en la Federación Obrera Local.

El conflicto de los obreros de la construcción demostró también que la misma contenía prácticas políticas y culturales izquierdistas. Por ejemplo, que comunistas, socialistas y radicales convergieran en la F.O.L. y que estuvieran identificados con la lucha y la causa obrera, durante y después de la huelga, según el relato de uno de los entrevistados, sin hacer una distinción ideológica ni política, daría cuenta de la existencia de prácticas izquierdistas de los obreros riocuartenses. O también, en las Actas de la F.O.L. se encuentran invitaciones a la federación de actos que realizaban en común el PS con la U.C.R. De la misma manera, una nota enviada por el Centro Socialista, que tras un congreso ordinario del PS resolvió hacer un "frente popular", invitando a la U.C.R. y al PC a participar del mismo. ${ }^{63}$ Estos ejemplos demostrarían que estas prácticas izquierdistas surgían de la misma experiencia de vida de estos trabajadores, más que de posturas ideológicas o políticas. Sus historias de vida estuvieron marcadas por el hambre y el trabajo, lo que forjó "estructuras de sentimientos" un "sentido común" que consideraba correcta la prédica 
de los obreros y militantes como José Cagnetta, Eulogio Astrada, Marcelino Reynoso, los hermanos Cedriani, Ernesto Biassi, Andrés Lazzisuch. Estos pioneros, como los recuerdan, antes que militantes comunistas o socialistas eran compañeros que tenían experiencias de vida similares. Algunos de ellos eran hijos de obreros inmigrantes. Otros provenían de las zonas rurales y se habían ido a Río Cuarto a trabajar en la construcción. El proceso de politización y el ingreso a un partido de izquierda en estos obreros fue el resultado de una experiencia en común que los llevó de tener una conciencia de "clase en sí" a una conciencia de "clase para sí".

Esta cultura izquierdista puede percibirse también en la respuesta que tuvo la sociedad riocuartense, básicamente los sectores populares y algunos profesionales vinculados a los radicales rojos y al mismo PC, ante el conflicto llevado adelante por los obreros de la construcción. Que la Federación Obrera Local, más precisamente, que su dirigente, José Cagnetta llamara a un paro general y que una buena parte de la sociedad riocuartense respondiera paralizando la ciudad, "sin siquiera que saliera el diario", daría cuenta de una sociedad receptiva a prácticas izquierdistas. Esto también puede apreciarse en la solidaridad llevada a cabo por las mujeres de los huelguistas. La confección de un bono solidario para ayudar a los trabajadores y las familias de estos, las colectas, la entrega de pan y leche en barrios como Banda Norte (la Pequeña Rusia) y Alberdi por parte de las panaderías y lecheros. El Centro Femenino organizaba, a su vez, bailes a beneficio de los huelguistas en el local de la F.O.L. O también, el manifiesto apoyo del abogado radical Zabala Ortiz darían muestra de una sociedad que se identificó con los obreros en lucha, que era solidaria y veía bien el reclamo de los huelguistas.

Por último, el reconocimiento del sindicato, uno de los estandartes del PC, fue bien acogido entre los trabajadores riocuartenses. A raíz de la huelga, se conformaron nuevos sindicatos, como por ejemplo el de la construcción, que reunió a todos los oficios afines en el Sindicato Único de la Construcción. También, los obreros rurales se incorporaron a la federación obrera, que creció en el número de afiliados como en la cantidad de gremios que se incorporaron.

\section{NOTAS}

1 Véanse los informes de la Federación Obrera Departamental del año 1936. En Archivo personal de Víctor Barrios.

2 BIALET MASSÉ, Juan. El estado de las clases obreras argentinas a comienzo del siglo, Córdoba: Universidad Nacional de Córdoba, Dirección General de Publicaciones, 1968. Original de 1904.

3 Véase La Voz del Interior de los años 1935 y 1936. 
4 Véase las Actas de la Federación Obrera Departamental de los años 1936 y 1937. Archivo personal de Víctor Barrios.

5 Véase La Voz del Sud del mes de enero 1906. Luego de una huelga su reclamo, un aumento de tarifas, se convirtió en una Ordenanza Municipal. La huelga fue previa a la Ordenanza Municipal que se aprobó el 16 de enero.

6 WILLIAMS, Raymond. The Long Revolution, Harmondsworth: Penguin, 1965, págs. 5770.

7 Véase El Imparcial, diario local del mes de mayo de 1916 y 1917.

8 Véase El Civismo, diario local del mes de septiembre de 1919.

9 Véase El Trabajo, diario local del mes de junio de 1923. El incidente con el lechero es del día 19 de junio.

10 Véase El Trabajo del día 5 de mayo de 1924.

11 Vicente Mojica había sido de la U.C.R. pero por diferencias internas se fue del partido y creó el partido vecinalista Liga de Defensa Comunal.

12 Véase El Trabajo del día 30 de mayo de 1930.

13 Véase sobre el conflicto de los obreros albañiles porteños de 1936 DURRUTY, Celia. "La Federación Obrera Nacional de la Construcción" en DI TELLA, Torcuato (comp.) Sindicatos como los de antes... Buenos Aires: Editorial Biblos, 1993, págs. 64 a 80. Clase obrera y peronismo, Op. Cit. Págs. 78 a 91. ISCARO, Rubens. Historia del movimiento sindical, Buenos Aires: Fundamentos, 1973, Tomo II. pág. 14 a 38. CHIARANTE, Pedro. Pedro Chiarante, ejemplo de dirigente obrero clasista. Memorias, Buenos Aires: Fundamentos, 1976, pág. 86 a 107. BURGAS, Miguel. El primer diputado comunista. Año 1924, Buenos Aires: Anteo, Colección Testimonios, 1985 Págs. 46 a 75. IÑIGO CARRERA, Nicolás. La estrategia de la clase obrera. 1936, Buenos Aires: Editorial PIMSA, 2000, págs. 123 a 191. CAMARERO, Hernán Comunismo y movimiento obrero en la Argentina 1914-1943, Buenos Aires: Editorial Siglo XXI, 2007. Págs. 322 a 336.

14 Véase sobre los pioneros del movimiento obrero riocuartense BARRIOS, Víctor Rescate a los pioneros. Río Cuarto: Imprenta de la Universidad de Río Cuarto, 2000.

15 Actas de la Federación Obrera Departamental de Víctor Barrios. Carpeta del año 1936.

16 Véase el diario local El Trabajo y La Voz del Interior del día 8 y 9 de enero de 1936

17 Véase el diario local El Trabajo y La Voz del Interior del día 9 de enero de 1936

18 Correspondencia entre José Cagnetta y Andrés Lassizuch en Archivo personal de Víctor Barrios.

19 Véase el diario local El Trabajo y La Voz del Interior del día 14 de enero de 1936.

20 Algunos de los empresarios de la construcción de Río Cuarto que formaban el Centro de Constructores eran: José de Marco, los hermanos Amati, Pablo Pozobón, Alejandro Brozina, Roque Carmini, Bartolomé Zupán, sólo por nombrar algunos de ellos.

21 Véase el diario local El Trabajo del día 15 de enero de 1936.

22 Carta enviada por el Centro de Constructores a la F.O.L fechada el día 16 de enero de1936. Archivo personal de Víctor Barrios.

23 Véase La Voz del Interior del día 18 de enero de 1936. 
24 Carta del Centro de Constructores de Río Cuarto enviada a la F.O.L. fechada el día 19 de enero de 1936. Archivo personal de Víctor Barrios.

25 Carta de la F.O.L enviada al Centro de Constructores de Río Cuarto fechado el día 19 de enero de 1936. Archivo personal de Víctor Barrios.

26 Véase La Voz del Interior del mes de enero de 1936

27 Marcelino Reynoso era obrero sastre y junto a Juan Cedriani fundaron el Sindicato de Sastres y Anexos. Ambos eran miembros del PS y compartían con los comunistas la dirección de la Federación Obrera Local.

28 Esto puede constatarse en las Actas de la Federación Obrera Local y en los diarios locales.

29 Véase el diario local El Trabajo y La Voz del Interior del día 25 de enero de 1936.

30 Pliego de condiciones del día 21 de enero de 1936. Archivo personal de Víctor Barrios.

31 Pliego de condiciones del día 4 de febrero de 1936 en el Archivo personal de Víctor Barrios.

32 Carta enviada al gobernador electo Amadeo Sabattini el día 11 de abril de 1936. Archivo personal de Víctor Barrios. El diario La Voz del Interior informa sobre esta carta el día 19 de abril de 1936.

33 Véase La Voz del Interior del día 28 de mayo de 1936

34 Miguel Burgas fue un protagonista activo de la organización de la huelga de la construcción del año 1936 en Capital Federal. Véase BURGAS, Miguel. El primer diputado comunista. Año 1924. Op. Cit. Págs. 46 a 75.

35 Carta dirigida por el Dr. Miguel A. Zabala Ortiz a la F.O.L. fechada el día 20 de enero de 1936. Véase Archivo personal de Víctor Barrios.

36 BARRIOS, Víctor. Op. Cit. Pág. 33.

37 Actas de Constitución del Sindicato de Único de la Construcción de Río Cuarto. 12 de octubre de 1936. Archivo personal de Víctor Barrios.

38 Véase al respecto CAMARERO, Hernán. A la conquista de la clase obrera. Los comunistas y el mundo del trabajo en la Argentina, 1920-1935, Op. Cit. Págs. 212 a 214. DI TELLA, Torcuato. Perón y los sindicatos. El inicio de una relación conflictiva, Buenos Aires: Editorial Ariel Historia, 2003, pág. 317 a 319. DOYON, Louise, M. Perón y los trabajadores. Los orígenes del sindicalismo peronista, 1943-1955, Buenos Aires: Editorial Siglo XXI, 2006, págs. 39 a 41. MATSUSHITA, Hiroshi. Movimiento obrero argentino. Sus proyecciones en los orígenes del peronismo, Buenos Aires: Ediciones Siglo Veinte, 1983, pág 165. DEL CAMPO, Hugo. Sindicalismo y peronismo...Buenos Aires: Editorial CLACSO, 1983Págs. 136 a 140.

39 Véase entrevista a Víctor Barrios, Río Cuarto, año 2006.

40Víctor Barrios murió en el invierno de 2007, cuando salía de una reunión política, a los 81 años. Su familia conserva el archivo original. El mismo ha sido digitalizado, pero no tiene una organización por temas sino en el mejor de los casos por años en distintas carpetas.

41 Acta del plenario de la F.O.L. del día 19 de julio de 1936. Aunque para la organización del acto del $1^{\circ}$ de mayo de 1936, los documentos ya hablan de la Federación Obrera Departamental. Archivo personal de Víctor Barrios.

42 BARRIOS, Víctor. Rescate a los pioneros. Op. Cit. pág. 28 
43 Actas de la Federación Obrera Departamental de Río Cuarto. Archivo personal de Víctor Barrios.

44 Carta enviada por el PC y la Juventud Comunista a la F.O.L. el día 23 de marzo de 1936. Archivo personal de Víctor Barrios.

45 Véase BARRIOS, Víctor. Op. Cit. Pág. 11

46 Actas del Congreso de la F.O.L. del 20 de junio de 1936. Archivo personal de Víctor Barrios.

47 Volante de la F.O.L. del año 1936. Archivo personal de Víctor Barrios.

48 Actas de la Federación Obrera Departamental de Río Cuarto. Archivo personal de Víctor Barrios. 20 de julio de 1936.

49 Actas de la Federación Obrera Departamental de Río Cuarto. Archivo personal de Víctor Barrios. 20 de julio de 1936.

50 Acta de la Federación Obrera Departamental que informa sobre el mitin realizado el día 18 de noviembre de 1936. Archivo personal Víctor Barrios.

51 Informe de Eulogio Astrada a la Federación Obrera Departamental del día 20 de febrero de 1936.

52 Acta de la Federación Obrera Departamental del día 5 de noviembre de 1938. Archivo personal de Víctor Barrios.

53 Río de los Sauces queda a 40 kilómetros de Río Cuarto.

54 Correspondencia de José Cagnetta y Andrés Lassizuch de los años 1937 y 1938. Archivo personal de Víctor Barrios.

55 Manifiesto de la Federación Obrera Departamental del día 30 de julio de 1938. Archivo personal de Víctor Barrios.

56 Actas de la Federación Obrera Departamental de los años 1936, 1937 y 1938. Archivo personal de Víctor Barrios.

57 Actas del año 1938 de la Federación Obrera Departamental del año 1938. Archivo personal de Víctor Barrios.

58 Carta de la Federación Obrera Ferroviaria del día 19 de agosto de 1936. Archivo personal de Víctor Barrios.

59 Nota en las Actas de la Federación Obrera Departamental que describe el recibimiento de este músico, fechada el 22 de mayo de 1938. Archivo personal Víctor Barrios.

60 Carta del día 16 de septiembre y de $1^{\circ}$ de octubre de 1936. Archivo personal Víctor Barrios.

61Carta del día 21 de septiembre del año 1936. Archivo personal de Víctor Barrios.

62 Las películas que se proyectaban eran básicamente del realismo ruso. Entre algunas de ellas "El milagro de Iván", "Octubre", "El acorazado de Potemkin".

63 Invitación al homenaje a Roque Saenz Peña realizado por el PS y la U.C.R. del día 16 de septiembre de 1936. También, nota del PS del día 3 de julio del año 1936. Archivo personal de Víctor Barrios.

Artigo recebido em julho de 2015. Aceito em setembro de 2015. 